Review Article

\section{Subungual exostosis: Pediatric aspects}

\section{Mohamed Anouar Dendane, Achraf El Bakkaly*, Zakaria Alami Hassani and Abdelouahed Amrani}

Department of Child Science, Faculty of Medicine and Pharmacy, Mohamed V University, Rabat, Morocco

\section{Introduction}

Subungual exostosis (SUE) is a benign phalangeal tumor of an osteocartilaginous nature [1]. SUE is most commonly diagnosed in children and young adults; most of these lesions are located in the big toe, although they can occur (albeit infrequently) in other toes. We report five observations of SUE described in young children under 10 years and discuss the particularities of this pathology in the pediatric population.

\section{Patients and Methods}

After having taken the agreement of the parents of all our patients, we retrospectively reviewed the cases of SUE treated and monitored by 2 surgeons at the children's hospital of Rabat between January 2010 and December 2016, ten SUE in patients under 16 years were identified. We defined the following inclusion criteria: patients aged less than 10 years at the time of the consultation, a diagnosis made on front and side X-rays, a histological confirmation and a followup greater than 24 months. Five cases met these criteria. Surgical treatment was performed in all patients and general anesthesia was consistently associated with locoregional block. The results of the treatment were analyzed according to the criteria mentioned in table 1 (loss of pain, healing time, presence or absence of onychodystrophy).

\section{Results}

Four patients were female. The average age was 7 years old. The exostosis sat under the toenail of the big toe in 2 cases. The other locations were the $2^{\text {nd }}$ and $3^{\text {rd }}$ toe. The right foot was the most affected in 4 cases. The concept of tight footwear was present in all children. The notion of direct trauma was only reported in one child. The time to diagnosis before diagnosis ranged from 3 to 10 months (mean: 7 months). The telltale symptom was constantly a pain aggravated by the shoes. The diagnosis was made in the presence of an infected ulcer lifting the nail in its central part and deforming it in two patients (Figure 1) and a submucosal pigmented surface in the other 3 (Figure 2). Radiography always showed a mass

\section{More Information}

*Address for Correspondence: Achraf El Bakkaly, Department of Child Science, Faculty of Medicine and Pharmacy, Mohamed V University, Rabat, Morocco, Tel: 212537670294; Email: achraf.elbakkaly1@gmail.com

Submitted: 10 June 2019

Approved: 25 July 2019

Published: 26 July 2019

How to cite this article: Dendane MA, El Bakkaly A, Hassani ZA, Amrani A. Subungual exostosis: Pediatric aspects. Arch Surg Clin Res. 2019; 3 : 056-058.

DOI: 10.29328/journal.ascr.1001034

Copyright: (c) 2019 Dendane MA, et al. This is an open access article distributed under the Creative Commons Attribution License, which permits unrestricted use, distribution, and reproduction in any medium, provided the original work is properly cited

Check for updates attached to the head of the last phalanx of the toe (Figure 3). The surgical approach was selective by the lateral route in 3 cases (Figure 4), and directly on the lesion combined with a trans-ungueal approach in 2 patients (Figure 5). The gesture consisted of excision of exostosis, curettage of its phalangeal implantation base and reconstruction of the nail bed.

At last follow-up (mean: 34 weeks), the result is good in 3 patients and average in 2 others. The main results are summarized in table 2 .

\begin{tabular}{|c|c|c|c|}
\hline \multicolumn{4}{|l|}{ Table 1: Criteria for assessment of the results. } \\
\hline Period & Pain disappearance & Healing delay & Onychodystrophy \\
\hline Good & Less than 2 weeks & Less than 4 weeks & No \\
\hline Medium & More than 2 weeks & More than 4 weeks & No \\
\hline Bad & Recidivism & Infection trailing & Yes \\
\hline
\end{tabular}

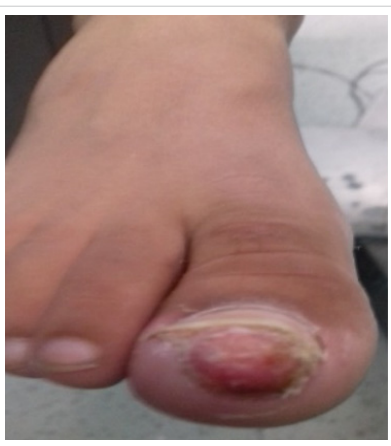

Figure 1: Ulcerative ungual exostosis of the big toe (the tumor is centrally developing, lifting and deforming the nail). 


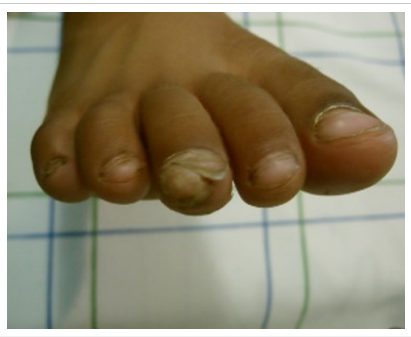

Figure 2: Subungual exostosis with lateral development of the 3rd toe.

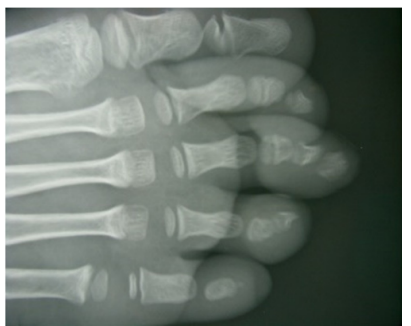

Figure 3: X-ray image showing a bone outgrowth with lateral development and detached from the distal phalanx of the 3rd toe.
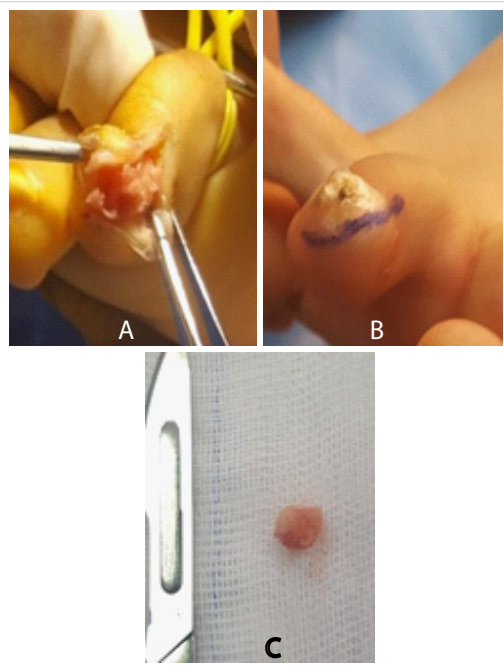

Figure 4: A- Lateral side facing shark of 3rd toe SUE / B- Exposure of the tumor and respect for the ungual matrix. / C- Resection part.

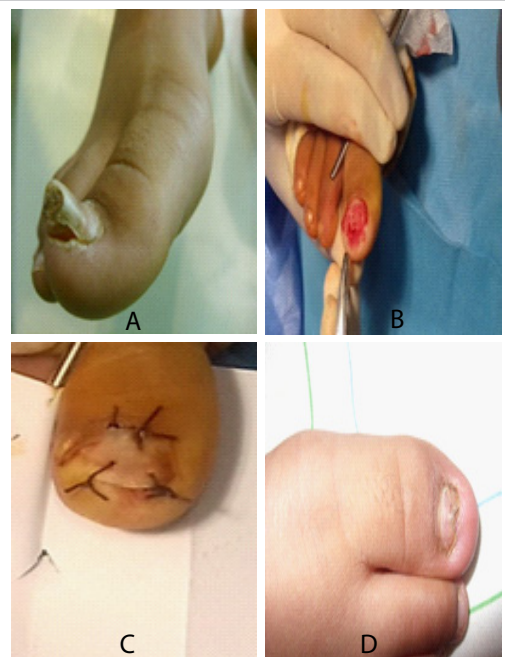

Figure 5: A: Exostosis of the big toe. Note nail deformation; B: Resection of the tumor initially trans-ungual; C: Restitution of the nail at the end of the procedure; D: Onychodystrophy at last follow-up.

\begin{tabular}{|c|c|c|c|c|c|c|c|c|}
\hline \multicolumn{7}{|l|}{ Table 2: Characteristics of patients. } \\
\hline Case & Age (year) & Sex & Time dg & Topography & Access & Evolution & $\begin{array}{c}\text { Recul } \\
\text { (Months) }\end{array}$ \\
\hline 1 & 9 & F & 3 & $\begin{array}{c}\text { 2nd Right } \\
\text { Toe }\end{array}$ & Selective & Good & 48 \\
\hline 2 & 6 & F & 10 & $\begin{array}{c}\text { Right Big } \\
\text { Toe }\end{array}$ & $\begin{array}{c}\text { Trans } \\
\text { ung }\end{array}$ & Medium & 36 \\
\hline 3 & 8 & F & 8 & $3^{\text {rd }}$ Right Toe & Selective & Good & 40 \\
\hline 4 & 7 & F & 5 & $\begin{array}{c}3^{\text {rd }} \text { Left Toe } \\
\text { Selective }\end{array}$ & Good & 24 \\
\hline 5 & 5 & M & 9 & $\begin{array}{c}\text { Right Big } \\
\text { Toe }\end{array}$ & $\begin{array}{c}\text { Trans } \\
\text { ung }\end{array}$ & Medium & 24 \\
\hline F: Female; M: Male; Dg: Diagnostic; Time in months; ung: ungula & \\
\hline
\end{tabular}

\section{Discussion}

SUE is a fairly rare tumor. She usually sees herself during the 2 nd and 3rd decades of life $[1,2]$. Due to the close-fitting and narrow structure $(1-2 \mathrm{~mm})$ of the subungual space, any type of occupying lesion may disturb the distal phalanx and cause pain. Reports on the misdiagnosis and incorrect treatment, or delayed diagnosis and treatment, of SUE are common in the literature $[1,3]$.

Very few series have reported pediatric cases during the first decade [3]. In the work of Piccolo et al, 2 patients were under 10 years of age [4]. Other authors have reported sporadic cases $[5,6]$. In our context, half of the SUE cases noted in patients less than 16 years of age involved children less than 10 years of age. The precise etiology of this lesion remains uncertain. The occurrence of SUE in young children is incriminating a genetic predisposition. The association with the disease of multiple exostoses is exceptional and concerns only the digital locations [7]. Moreover, the hypothesis that the translocation $t(X ; 6)$ (q13-14; q22) would lead to the mutation of the COL12A1 and COL4A5 collagen genes and the formation of ESU's seems interesting but has not been verified by other authors [8].

We estimate, like Letts, that the repetitive micro trauma represented in our study by the tight fitting reported in all the patients would be at the origin of a rupture of the perichondrium, resulting from cells of growth and formation of the exostoses [3]. Exostoses are localized more than nine times out of ten on the foot and very largely under the toenail of the big toe $[1,2,9]$. This predilection is probably less obvious in young children. In the pediatric series of Letts et al. [3], one-third of the locations spared the first toe. The 2 children aged 6 in the Picollo et al series had a first ray unharmed [4]. Finally, three of our five cases were on the 2 nd or 3 rd toe.

In terms of diagnosis and in contrast to the exostoses of the adult in whom several nail lesions or nail bed should be eliminated because of their frequency or resemblance to the SUE, the damage in the young child poses a diagnostic problem differential mainly with:

- The phalanx osteochondroma mono-regular, rare and usually located on the middle part of the proximal phalanx. 
- Osteochondroma, which is rarely localized at the toes and which originates in the metaphysis of the proximal phalanx.

The X-ray allows to cut by showing in case of SUE a limited opacity of the distal tip of the last phalanx, lateral development and very often detached from the phalanx because largely cartilaginous in young children (Figure 3). The clinical dimension is much larger than the radiological size. Histology confirms the diagnosis by highlighting an osteocartilaginous lesion similar to osteochondroma but different from the latter by the presence of a fibro cartilaginous cap rather than hyaline cartilage $[4,10]$. Recently, Piccolo et al reported the value of performing a dermoscopic diagnosis [4]. We believe that this examination is of little interest to young children.

If surgical treatment is the rule regardless of the age of the patient, the management of the SUE at a young age imposes more precautions with respect to the bed and the matrix of the nail, in particular because of its weak size and its great fragility. We performed a selective lateral approach for the locations outside the big toe. These were SUE devices that have evolved very well. On the other hand, the central exostoses of the big toe are often only affordable by direct means [11]. In 2 of our patients, we combined the direct approach to exostoses with a transgene pathway requiring total nail rejection and end-of-procedure restoration. One of our patients developed onychodystrophy. This complication remains frequent in the central locations of the SUE [2], and we estimate like Haneke \& al. that the dystrophy results more from the destruction of the matrix of the nail by the tumor itself than the iatrogenic action of the surgeon on the bed and the subungual growth structure [12]. In all cases, complete resection of the exostoses based on the principle of safeguarding the vitality of the nail matrix and including the base of implantation of the tumor on the phalanx until visualization of the cancellous bone is obligatory and allows protecting the child from recidivism, which represents $10 \%$ and $20 \%$ of cases $[3,11]$. No recurrence was noted in our patients but we deplore 2 average results at the locations on the big toe. It was onychodystrophy in one and delayed healing in the other.

\section{Conclusion}

SUE is a benign and uncommon lesion that is infrequently noticed by physicians. This may result in delays in diagnosis and treatment. Therefore, it is important that SUE is included in the differential diagnosis of toe-tip pathologies [13]. Early suspicion of SUE should lead to radiography to verify the diagnosis and prompt surgical excision if the SUE is confirmed. Radiography may be useful in the differential diagnosis of SUE, while local excision of the mass with the overlying fibro cartilaginous cap is the preferred treatment. Removal of adjacent unaffected bone may prevent local recurrence, and repair of the nail bed can provide better outcomes $[14,15]$.
The SUE of early onset at a young age could be prevented by crowding out tight footwear and its prognosis improved by early diagnosis. This prevents the superinfection of the lesions and the suffering of the bed and the nail matrix all the more fragile as the child is young.

\section{References}

1. Ibrahimi EA, Daoudi A, Shimi M , E Mrini A, Boutayeb F. Subungual exostoses of the great toe. Med Chir Pied. 2009; 25: 9-12.

2. Richert B, Lecerf $P$, Caucanas $M$, André J. Clin in Dermatol. 2013; 31: 602-617.

3. Letts $M$, Davidson D, Nizalik E. Subungual exostoses: diagnosis and treatment in children. J Trauma. 1998; 44: 346-349. PubMed: https://www.ncbi.nlm.nih.gov/pubmed/9498509

4. Piccolo V, Argenziano G, Alessandrini AM, Russo T, Starace $M$, et al. Dermoscopy of subungual exostosis: a retrospective study of 10 patients. Dermatol. 2017; 233: 80-85. PubMed: https://www.ncbi.nlm.nih.gov/pubmed/28482347

5. Wollina U, Baran R, Schônlebe J. Dystrophy of the great toenail by subungual exostosis and hyperostosis: three case reports with different clinical presentations. Skin Appendage Disord. 2015; 1: 213-216. PubMed: https://www.ncbi.nlm.nih.gov/pmc/articles/PMC4908449/

6. Miguel-Gómez L, Fonda-Pascual $P$, Vañó-Galván $S$, Jaen-Olasolo P. Subungual exostosis. An Pediatr (Barc). 2015; 82: 443-444. PubMed: https://www.ncbi.nlm.nih.gov/pubmed/25649672

7. Francannet $\mathrm{C}$, Cohen-Tanugi A, Le Merrer M, Munnich A, Bonaventure $J$, et al. Genotype-phenotype correlation in hereditary exostoses. J Med Genet. 2001; 38: 430-434. PubMed: https://www.ncbi.nlm.nih. gov/pubmed/11432960

8. Storlazzi CT, Wozniak A, Panagopoulos I, Sciot R, Mandahl N, et al. Rearrangement of the $\mathrm{COL} 12 \mathrm{~A} 1$ and $\mathrm{COL} 4 \mathrm{~A} 5$ genes in subungual exostosis: molecular cytogenetic delineation of the tumor-specific translocation $\mathrm{t}(\mathrm{X} ; 6)$ (q13-14; q22). Int J Cancer. 2006; 118: 19721976. PubMed: https://www.ncbi.nlm.nih.gov/pubmed/16284948

9. Cohen H, Frank S, Winkin W, Gibbs R. Subungual exostosis. Arch Dermatol 1973; 107: 431-432.

10. Jeong $\mathrm{KH}$, Lee $\mathrm{MH}$. The clinical histopathological and radiological findings of subungual exostosis. Korean J Dermatol. 2009; 47: 43-49.

11. Fikry T, Dkhissi M, Harfaoui A, Adil A, Haddoun A, et al. Les exostoses sous unguéales. Etude rétrospective d'une étude de 28 cas. Acta Ortho Belg. 1998; 64: 35-40.

12. Haneke E, Di Chiacchio N, Richert B. Surgery for the bony phalanx. Nail surgery. $2011 ; 149-164$.

13. Malkoc M, Korkmaz O, Keskinbora M, Seker A, Oltulu I, et al. Surgical treatment of nail bed subungual exostosis. Singapore Med J. 2016; 57: 630-633. PubMed: https://www.ncbi.nlm.nih.gov/pmc/articles/ PMC5331139/

14. Tuzuner T, Kavak A, Parlak AH, Ustundag N. Subungual osteochondroma: a diagnostic dilemma. J Am Podiatr Med Assoc. 2006; 96: 154-157. PubMed: https://www.ncbi.nlm.nih.gov/pubmed/16546954

15. García Carmona FJ, Pascual Huerta J, Fernández Morato D. A proposed subungual exostosis clinical classification and treatment plan. J Am Podiatr Med Assoc. 2009; 99: 519-524. PubMed: https://www.ncbi.nlm.nih.gov/pubmed/19917738 